\title{
Studi Komparatif Tingkat Value Added Antara Usaha Ternak Sapi Pola Integrasi Dengan Pola Mandiri (Studi Kasus Pada PT. Integrasi Sawit Sapi Batang Hari Dengan Masyarakat Desa Petajen)
}

\author{
Sri Rosmawati, Yaasin Waspodo \\ Sekolah Tinggi Ilmu Graha Karya Muara Bulian \\ Correspondence email: srirosmawati44@yahoo.com
}

\begin{abstract}
This research is a comparative study between the integration of cattle with independent patterns (Case Study at PT. Batang Sawit Palm Integration with Petajen villagers). The purpose of this research is (1) to find out the cost component of the integration of cattle production patterns at PT Batang Batang Hari Integration with the independent pattern of the Petajen village community. (2) to find out the basic cost of beef cattle production in the integration pattern in PT Batang Hari Cow Integration with the independent pattern of the Petajen village community. (3) to find out the level of value added of cattle integration business pattern in PT Batang Hari Cow Integration with the independent pattern of Petajen village community. The research method used in this research is quantitative descriptive, by looking for a comparison (comparative) between cattle business integration patterns in PT Batang Batang Hari Integration with independent patterns of Petajen village community. From the research results obtained the results of the level of value added (added value) in every sale of one cow in the integration pattern of Rp. 3,187,500, while the level of value added in each sale of one cow in the independent pattern is Rp.1,146,000. The level of value added (value added) in the integration pattern is greater than the level of value added in the independent pattern.
\end{abstract}

Keyword: Comparative studies, Value added, cattle, independent patterns

\section{PENDAHULUAN}

Kebutuhan daging sapi dari tahun ke tahun terus meningkat seiring dengan pertambahan jumlah penduduk dan pendapatan masyarakat serta kesadaran tentang gizi. Sementara produksi daging sapi di Indonesia masih belum bisa memenuhi keseluruhan kebutuhan daging sapi. Pemerintah masih harus mengimpor daging sapi dari luar negeri untuk menutupi kebutuhan daging sapi nasional. Proyeksi produksi daging sapi dalam negeri pada tahun 2019 hanya menutupi sekitar 62 persen dari total kebutuhan daging sapi. Impor daging sapi dilakukan baik dengan mengimpor daging beku maupun sapi hidup berupa sapi bakalan.

Untuk memenuhi kebutuhan daging sapi dalam negeri sebagian besar di hasilkan oleh usaha ternak masyarakat perorangan dan dilakukan dengan cara tradisional. Namun, tidak sedikit pula usaha ternak sapi dilakukan oleh pengusaha. Usaha penggemukan sapi potong merupakan usaha yang potensial dalam rangka pemenuhan kebutuhan daging sapi nasional.

Namun demikian perlu diidentifikasi alternatif pola-pola pengembangan peternakan rakyat atau masyarakat yang mempunyai skala usaha yang ekonomis yang mampu memberikan kontribusi terhadap pendapatan keluarga yang cukup memadai. Sebagai wilayah untuk pengembangan usaha ternak sapi didasarkan pada beberapa alasan penting diantaranya adanya potensi sumber daya alam dan sumber daya manusia yang tersedia dan potensial untuk dikembangkan, adanya pasar hewan, jumlah ternak yang cukup, dan letak geografi yang strategis. Melihat kondisi tersebut maka desa Petajen, masih mempunyai peluang untuk dilakukan pengembangan lebih lanjut.

Salah satu usaha peternakan yang banyak dilakukan oleh masyarakat perdesaan adalah beternak sapi yang berbentuk usaha peternakan masyarakat. Usaha peternakan sapi di Desa Petajen umumnya masih didominasi oleh beberapa warga yang mempunyai ternak sapi yang berhubungan dengan usaha tani lainnya. Peternakan hanya dilakukan sebagai usaha sambilan, sedangkan usaha yang utama adalah bertani.

Dalam pengembangan usaha ternak sapi, bagi pengusaha ternak sapi tentu saja membutuhkan investasi yang tidak sedikit. Untuk dapat mencapai keuntungan yang diharapkan, pengusaha ternak sapi perlu memperhitungkan biaya produksi yang dikeluarkan. Peternakan sapi secara tradisional pun seharusnya juga memperhitungkan berapa biaya produksi yang mereka keluarkan dalam peternakan sapi mereka. Hal ini tentu saja agar mereka juga memperoleh keuntungan yang memadai dari pemeliharaan ternak mereka.

Pada tahun 2011 di Desa Petajen Kecamatan Bajubang ada satu keluarga yang memulai berternak sapi atau memelihara sapi dengan jumlah bibit sapi yang di miliki oleh keluarga tersebut berjumlah 6 ekor sapi, diantaranya 2 ekor sapi jantan dan 4 ekor sapi betina. Pola yang dilakukan oleh peternak ini tentu saja masih pola tradisional. Sedangkan pada tahun 2012, PT Integrasi Sawit Sapi Batang Hari membuat usaha perternakan sapi integrasi dengan kelapa sawit yang di namakan ISS (Integrasi Sawit Sapi) yang merupakan 
usaha peternakan sapi terintegrasi dengan kelapa sawit. Pengembangan usaha integrasi sawit dan sapi ini didasarkan pada pemikiran pemanfaatan sumber daya pada suatu komoditas bagi pengembangan komoditas lain guna mendorong terciptanya integrasi saling menguntungkan. Pemanfaatan pelepah sawit sebagai sumber pakan ternak dan pemanfaatan kotoran ternak sebagai pupuk organik untuk memenuhi kebutuhan pupuk tanaman kelapa sawit serta menyediakan kesempatan kerja kepada penduduk sekitar lokasi pengembangan usaha integrasi sawit sapi.

Berdasarkan dari kedua pola ternak sapi ini penulis tertarik untuk melakukan studi komparatif antara usaha ternak sapi pola integrasi dengan pola mandiri (Studi Kasus Pada PT. Integrasi Sawit Sapi Batanghari dengan masyarakat desa Petajen). Tujuan dilakukannya penelitian ini adalah (1) untuk mengetahui komponen biaya produksi ternak sapi pola integrasi pada PT Integrasi Sawit Sapi Batang Hari dengan pola mandiri masyarakat desa Petajen. (2) untuk mengetahui harga pokok produksi ternak sapi pola integrasi pada PT Integrasi Sawit Sapi Batang Hari dengan pola mandiri masyarakat desa Petajen. (3) untuk mengetahui tingkat value add usaha ternak sapi pola integrasi pada PT Integrasi Sawit Sapi Batang Hari dengan pola mandiri masyarakat desa Petajen.

\section{METODE}

Metode penelitian yang digunakan dalam penelitian ini adalah deskriptif kuantitatif, dengan mencari perbandingan (komparatif) antara usaha ternak sapi pola integrasi pada PT Integrasi Sawit Sapi Batang Hari dengan pola mandiri masyarakat desa Petajen. Alat analisa yang digunakan sebagai pemecah masalah yang akan dibahas adalah dengan menghitung dan menganalisa biaya produksi , Harga pokok produksi, harga pokok penjualan dan menentukan tingkat value add.

\section{HASIL DAN PEMBAHASAN Komponen Biaya Produksi Ternak Sapi Pola Integrasi Biaya Bahan Baku}

Biaya Bahan Baku Ternak Sapi Pola Integrasi berasal dari bibit sapi yang dibeli melalui pihak ketiga yang berasal dari provinsi Lampung. Kriteria yang dibeli adalah anakan sapi dalam kondisi sehat dan berumur satu setengah tahun dengan biaya Rp 9.000.000 sebanyak 300 ekor bibit sapi. Total biaya bahan baku adalah Rp 2.700.000.000. Biaya tenaga kerja langsung meliputi, karyawan pengambil pelepah sebanyak 5 orang tenaga kerja dengan gaji Rp. 2,400.000 per bulan.

Tabel 1. Biaya Tenaga Kerja Langsung Ternak Sapi Pola Integrasi

\begin{tabular}{ccccc}
\hline No & Volume & Gaji Per Orang & Biaya Tenaga Kerja Per Bulan & Biaya Tenaga Kerja Per Tahun \\
\hline 1 & 5 Orang & Rp. 2.400.000 & Rp. 12.000.000 & Rp. 144.000 .000 \\
& & Biaya Tenaga Kerja Langsung & Rp.144.000.000 \\
\hline
\end{tabular}

Sumber: Data Primer Diolah

Biaya Overhead Pabrik Ternak Sapi Pola Integrasi

Biaya Overhead Pabrik adalah semua biaya manufaktur yang tidak ditelusuri secara langsung ke output tertentu. Biaya overhead pabrik pada PT. Integrasi Sawit Sapi Batang Hari adalah sebagai berikut:

Tabel 2. Biaya overhead pabrik pada PT. Integrasi Sawit Sapi Batang Hari

\begin{tabular}{|c|c|c|c|c|}
\hline No & Keterangan & Volume & Harga (Rp) & Jumlah Biaya (Rp) \\
\hline 1 & Dedak & $360 \mathrm{hr}$ & Rp. $\quad 100.000$ & Rp. 36.000 .000 \\
\hline 2 & Jagung & $360 \mathrm{hr}$ & Rp. $\quad 100.000$ & 36.000 .000 \\
\hline 3 & Biaya Tenaga Kerja Tidak Langsung & $12 \mathrm{bln}$ & Rp. 72.000 .000 & Rp. 864.000 .000 \\
\hline 4 & Listrik & $12 \mathrm{bln}$ & Rp. $\quad 6.000 .000$ & Rp. $\quad 72.000 .000$ \\
\hline 5 & Solar & $12 \mathrm{bln}$ & Rp. 6.600 .000 & 79.200 .000 \\
\hline 6 & Oli & $12 \mathrm{bln}$ & Rp. $\quad 100.000$ & 1.200 .000 \\
\hline 7 & Perawatan Mesin & $12 \mathrm{bln}$ & 350.000 & 4.200 .000 \\
\hline 8 & Penyusutan & 1 thn & Rp. $\quad 750.000$ & Rp. $\quad 750.000$ \\
\hline 9 & Vitamin/Obat-Obatan & 12 bln & Rp. 1.200 .000 & Rp. $\quad 14.400 .000$ \\
\hline \multicolumn{4}{|c|}{ Jumlah Biaya Overhead Pabrik Ternak Sapi Pola Integrasi } & Rp. 1.107.750.000 \\
\hline
\end{tabular}

Sumber : Data Primer Diolah

Dari data diatas, diperoleh gambaran bahwa untuk memproduksi pakan per hari, guna memenuhi kebutuhan pakan sebanyak 300 ekor ternak sapi dalam satu tahun sebesar Rp. 1.107.750.000 maka biaya pakan ternak sapi per ekor sebesar Rp. 3.692.500 (Rp. 1.107.750.000 : 300 ekor sapi $=$ Rp. 3.692.500).

\section{Komponen Biaya Produksi Ternak Sapi Pola Mandiri} Biaya Bahan Baku Ternak Sapi Pola Mandiri

Biaya bahan baku ternak sapi pola mandiri adalah bibit sapi yang di beli dengan harga Rp. 7.000.000. Kriteria bibit yang dibeli adalah anakan sapi dalam kondisi sehat berumur 8 bulan sebanyak 6 ekor bibit sapi. Total biaya adalah Rp42.000.000. 
Sri Rosmawati dan Yaasin Waspodo, Studi Komparatif Tingkat Value Added Antara Usaha Ternak Sapi Pola Integrasi Dengan Pola Mandiri (Studi Kasus Pada PT. Integrasi Sawit Sapi Batang Hari Dengan Masyarakat Desa Petajen)

Biaya Tenaga Kerja Langsung Ternak Sapi Pola Mandiri

Biaya tenaga kerja langsung ternak sapi pola mandiri meliputi, tenaga kerja pengambil rumput meliputi 2 orang tenaga kerja dengan gaji per orang sebesar Rp. 500.000 per bulan. Biaya per bulan adalah
Rp 1.000.000. Total biaya tenaga kerja pertahun adalah Rp12.000.000. Oleh karena keterbatasan waktu, serta besar kemungkinan bahwa kemampuan serta biaya yang dikeluarkan oleh peternak pola mandiri, cenderung sama, maka dalam perhitungan pembahasan skripsi ini penulis hanya meneliti satu orang peternak warga masyarakat desa petajen.

Tabel 3. Biaya Overhead Pabrik Ternak Sapi Pola Mandiri

\begin{tabular}{|c|c|c|c|c|}
\hline No & Keterangan & Volume & Harga Jual (Rp) & Jumlah Biaya (Rp) \\
\hline 1 & Minyak Bensin & $12 \mathrm{bln}$ & Rp. 1.365 .000 & Rp. 16.380 .000 \\
\hline 2 & Oli & 4 kali & Rp. $\quad 300.000$ & Rp. $\quad 1.200 .000$ \\
\hline 3 & Biaya Tenaga Kerja Tidak Langsung & $12 \mathrm{bln}$ & Rp. 1.500 .000 & Rp. 18.000 .000 \\
\hline 4 & Biaya Listrik & $12 \mathrm{bln}$ & Rp. $\quad 300.000$ & Rp. 3.600 .000 \\
\hline 5 & Vitamin/Obat-Obatan & $12 \mathrm{bln}$ & 12.000 & Rp. $\quad 144.000$ \\
\hline \multicolumn{4}{|c|}{ Jumlah Biaya Produksi Pakan Ternak Sapi Pola Mandiri } & Rp. 39.324.000 \\
\hline
\end{tabular}

Sumber: Data Primer Diolah

Dari data diatas, diperoleh gambaran bahwa untuk memproduksi pakan per hari, guna memenuhi kebutuhan pakan sebanyak enam ekor ternak sapi dalam satu tahun sebesar Rp. 39.324.000 maka biaya produksi pakan ternak sapi per ekor adalah sebesar Rp. 6.554 .000 (Rp. 39.324.000 : 6 ekor sapi $=$ Rp. 6.554.000).

\section{Harga Pokok Produksi Ternak Sapi Pola Integrasi Dengan Pola Mandiri}

Harga Pokok Produksi Ternak Sapi Pola Integrasi adalah sebagai berikut:

Tabel 4. Harga Pokok Produksi Ternak Sapi Pola Integrasi

\begin{tabular}{|c|c|c|}
\hline No & Keterangan & Jumlah (Rp) \\
\hline 1 & Biaya Bahan Baku & Rp. 2.700.000.000 \\
\hline 2 & $\begin{array}{l}\text { Biaya Tenaga Kerja } \\
\text { Langsung }\end{array}$ & Rp. $\quad 144.000 .000$ \\
\hline 3 & Biaya Overhead Pabrik & Rp. 1.107 .750 .000 \\
\hline \multicolumn{2}{|c|}{$\begin{array}{l}\text { Jumlah Harga Pokok Produksi Pola } \\
\text { Integrasi }\end{array}$} & Rp. 3.951.750.000 \\
\hline
\end{tabular}

Harga pokok produksi per ekor sapi adalah Rp 13.172.500.

Tabel 5. Harga Pokok Penjualan Ternak Sapi Pola Integrasi

\begin{tabular}{cllr}
\hline No & \multicolumn{1}{c}{ Keterangan } & \multicolumn{2}{c}{ Jumlah (Rp) } \\
\hline 1 & Harga Pokok Produksi & Rp. 3.951.750.000 \\
2 & Gaji Pimpinan & Rp. & 84.000 .000 \\
3 & Sewa Mobil & Rp. & 108.000 .000 \\
Jumlah & Rp. 4.143 .750 .000 \\
Jumlah Harga Pokok Penjualan Sapi & Rp. & 13.812 .500 \\
& Pola Integrasi Per Ekor & \\
\hline
\end{tabular}

Menghitung Biaya Penjualan :

Gaji Pimpinan : Jumlah Sapi (Rp.84.000.000: 300 ekor = Rp. 280.000)

Sewa Mobil : Jumlah Sapi (Rp. 108.000.000: 300 ekor $=$ Rp. 360.000).

Biaya penjualan ternak sapi pola integrasi adalah sebesar Rp. 640.000
Harga pokok penjualan per ekor sapi adalah (Rp. 13.172.500 + Rp. $640.000=$ Rp. 13.812.500)

Tabel 6. Harga Pokok Produksi Ternak Sapi Pola Mandiri

\begin{tabular}{lll}
\hline No & \multicolumn{1}{c}{ Keterangan } & Jumlah \\
\hline 1 & Biaya Bahan Baku & Rp. 42.000 .000 \\
2 & Biaya Tenaga Kerja Langsung & Rp. 12.000 .000 \\
3 & Biaya Overhead Pabrik & Rp. 39.324 .000 \\
Jumlah Harga Pokok Produksi Ternak & Rp. 93.324 .000 \\
$\quad$ Sapi Pola Mandiri & \\
\hline
\end{tabular}

Sumber: Data Primer Diolah

Dari uraian diatas maka diperoleh harga pokok produksi per ekor sapi pada pola mandiri adalah sebesar Rp. 15.554.000.

Tabel 7. Harga Pokok Penjualan Ternak Sapi Pola Mandiri

\begin{tabular}{|c|c|c|}
\hline No & Keterangan & Jumlah \\
\hline 1 & Harga Pokok Produksi & Rp. 93.324 .000 \\
\hline 2 & Biaya Penjualan & \\
\hline & 1. Promosi & 600.000 \\
\hline & 2. Distribusi & Rp. $\quad 1.200 .000$ \\
\hline & Jumlah & Rp. 95.124 .000 \\
\hline & $\begin{array}{l}\text { umlah Harga Pokok Penjualan } \\
\text { rnak Sapi Pola Mandiri Per Eko }\end{array}$ & Rp. 15.854 .000 \\
\hline
\end{tabular}

Sumber : Data Primer Diolah

Jadi biaya penjualan ternak sapi pola mandiri yaitu sebesar Rp. 300.000 (Rp. $100.000+$ Rp. $200.000=$ Rp. 300.000). Menghitung harga pokok penjualan per ekor sapi:

Harga pokok produksi per ekor sapi + Biaya Penjualan (Rp. 15.554.000 + Rp. $300.000=$ Rp. 15.854.000). Harga pokok penjualan per ekor sapi pada pola mandiri adalah sebesar Rp.15.854.000

Analisis Tingkat Value Added (Nilai Tambah) Usaha Ternak Sapi Pola Integrasi dengan Pola Mandiri 
Sri Rosmawati dan Yaasin Waspodo, Studi Komparatif Tingkat Value Added Antara Usaha Ternak Sapi Pola Integrasi Dengan Pola Mandiri (Studi Kasus Pada PT. Integrasi Sawit Sapi Batang Hari Dengan Masyarakat Desa Petajen)

Tingkat Value Added (Nilai Tambah) Usaha Ternak Sapi Pola Integrasi

Dari hasil perhitungan diatas pada pola integrasi maka secara total tingkat value added usaha ternak sapi per ekor dengan harga jual secara rata-rata per ekor Rp. 17.000.000 dengan waktu pemeliharaan kurang lebih selama satu tahun. Sedangkan harga pokok penjualan sama dengan harga pokok produksi yaitu secara total keseluruhan sebesar Rp. 13.812.500, maka nilai value added (nilai tambah) adalah total cost dikurang total revenue (TC - TR) adalah sebesar Rp. 3.187.500, berarti tingkat value added (nilai tambah) dalam penjualan satu ekor sapi sebesar Rp. 3.187.500.

\section{Tingkat Value Added Usaha Ternak Sapi Pola Mandiri}

Dari hasil perhitungan diatas pada pola mandiri maka secara total tingkat value added, usaha ternak sapi pola mandiri per ekor dengan harga jual secara rata-rata per ekor Rp. 17.000.000 dengan waktu pemeliharaan kurang lebih selama satu tahun. Sedangkan harga pokok penjualan sama dengan harga pokok produksi yaitu secara total keseluruhan sebesar Rp. 15.854.000, maka nilai value added (nilai tambah) adalah total cost dikurang total revenue (TC - TR) adalah sebesar $\mathrm{Rp}$. 1.146.000, berarti tingkat value added (nilai tambah) dalam penjualan satu ekor sapi sebesar Rp. 1.146.000. Dari uraian diatas dapat disimpulkan tingkat value added (nilai tambah) pada pola integrasi lebih besar dari tingkat value added pada pola mandiri.

\section{SIMPULAN}

Berdasarkan hasil penelitian dapat disimpulkan:

1. Komponen biaya produksi pola integrasi terdiri dari, biaya bahan baku sebesar Rp. 2.700.000.000, biaya tenaga kerja langsung sebesar Rp. 144.000.000, biaya produksi pakan ternak sebesar Rp. 1.107.750.000. Komponen biaya produksi pola mandiri terdiri dari, biaya bahan baku sebesar Rp. 42.000.000, biaya tenaga kerja langsung sebesar Rp. 12.000.000, biaya produksi pakan ternak sebesar Rp. 39.324.000.

2. Harga pokok produksi pada pola integrasi sebesar Rp. 3.951.750.000, harga pokok produksi pada pola mandiri sebesar Rp. 93.324.000. Harga pokok penjualan ternak sapi pada pola integrasi sebesar Rp. 13.812.500, dengan harga jual rata-rata sebesar Rp. 17.000.000. Sedangkan ternak sapi pada pola mandiri harga pokok penjualan sebesar Rp. 15.854.000, dengan harga jual rata-rata sebesar Rp. 17.000.000.

3. Tingkat value added dalam setiap penjualan satu ekor sapi pada pola integrasi sebesar Rp. 3.187.500, sedangkan tingkat value added dalam setiap penjualan satu ekor sapi pada pola mandiri sebesar Rp.1.146.000. Tingkat value added pada pola integrasi lebih besar dari tingkat value added pada pola mandiri.

\section{DAFTAR PUSTAKA}

Williamson, Payne, 2010. Usaha Ternak Sapi Potong. Jakarta : PT. Gramedia

Mulyadi, 2010.Pengertian Biaya Produksi. Jakarta :Sinar Grafika

Hansen, Mowen, 2013. Pengertian Harga Pokok Produksi. Jakarta : Bumi Aksara

Kusnaidi, Sunarto, 2010. Pengertian Biaya Bahan Baku. Penerbitan Salemba : Jakarta

Haller, Stolowy, 2010.Pengertian Valeu Added. Jakarta : Erlanga

Fikar, 2010.Manajemen Usaha Tani. Pendidikan Nasional, Politeknik Pertanian Negri Jember.

Sahala et al. 2010. Problem Dan Prospek Pengembangan Usaha Pembibitan Sapi Potong Di Indonesia. Jurnal Agribisnis Pertanian.

Bastian Bustomi. 2010. Pengertian Biaya Produksi. Sinar Grafika

Suherman Rosyid.2010. Pengertian Biaya Produksi. Sinar Grafika

Suparmoko. 2010. Pengertian Biaya Produksi. Sinar Grafika

Supriyono. 2010. Pengertian Biaya-Biaya. Jurnal Akuntansi

STIE-GK, 2019.Buku Panduan Penulisan Skripsi. Muara Bulian

http://repository.widiyatama.ac.id/pengertianhargapokok produksi

http://www.beeclooud.id/menghitung-harga-pokokproduksi/ 